\title{
Designing Digital Scholarship Ecologies
}

$\begin{array}{ll}\text { Abstract } & 1\end{array}$

$\begin{array}{ll}\text { Introduction } & 1\end{array}$

Environment 2

What changes? $\quad 3$

Omnipresent $\quad 3$

Data Focused and Infrastructure Aware $\quad 4$

$\begin{array}{ll}\text { Essential to the community } & 6\end{array}$

$\begin{array}{ll}\text { Conclusion } & 6\end{array}$

$\begin{array}{ll}\text { Works Cited } & 7\end{array}$

\begin{abstract}
Digital Scholarship and Scholarly Communication are transforming the practice of librarianship by 1) integrating throughout the research process, 2) re-positioning the core of libraries, 3) increasing focus on "back of the house" processes/skills, 4) facilitating an outward orientation. Approaching these through the frames of design and ecology offer a useful re-imagining of our current state and possible futures.
\end{abstract}

\section{Introduction}

We've reached a moment where Digital Scholarship and Scholarly Communication are influential and mature enough that question has to be asked: how are these areas of work transforming institutions? We're also in a tumultuous moment for higher education, where the academy has given way to the research-intensive university, and is slowly evolving into the four year staging ground for the entrepreneurial enterprise. I propose that there are near-term revolutions that will produce a long-term evolution for the library, aligning with that shift while maintaining our values/ethics. I was never very interested in prophecy or prognostication, and not especially good at theory, so I'll do my best to center on concrete applications. However, there are two frames that I'd like to glance through - Design and Ecology - each offering a useful way for the library to see itself anew. Design because as Rachel Ivy Clarke posits practiced librarianship doesn't actually function as a social science, observing and describing the natural/information world, but rather as a discipline that creates things to solve problems (Clarke, 2018). Ecology because I'm tired of using the word infrastructure all 
the time, with its attendant technophiliac tendencies. Also, I've noticed increasing conversations about the ecosystem of academic publication, and I think it is worth exploring more deeply. Interactions between organisms and their environment, the wikipedia definition of ecology, feels much closer to the daily flux and nature of this work. So, this is me, a humanities major, failed pop culture scholar, and puzzling example of a librarian, with no domain expertise in design OR natural sciences, attempting to pull it all together in a nice theory of everything. Game on.

\section{Environment}

- Scholarly communication (open access, repository development, copyright support)

- Data services (management, literacy, visualization, curation)

- Digital humanities (projects, training, community development)

- Library publishing

- Open Educational Resources

- Digital pedagogy

Let's start with bedrock - a holistic view of "digital scholarship", in my opinion, includes all the activities that we've been struggling to affix in offices of digital scholarship, scholarly communication teams, and data curation working groups. These activities/programs/initiatives include things like - library publishing, open access advocacy, repository development, data visualization, digitization, digital humanities projects, open educational resources, and more. The term "digital scholarship" represents the common characteristics of these activities - radically prone toward openness, (currently) innovative in our field, technology-dependent, interested in a container/format(s) agnostic future, predisposed toward new or emerging research methods, and typically project-based (Moritz et al., 2017).

Another characteristic of these activities that transforms the library is the laser-like focus of each of these on the creation of a thing, or the production of an output. Clarke writes that in essence, design "hinges on the action of creation... [including] intangible conceptual systems, which then may be represented by or documented in physical artefacts" (2018). The Periodic Table of Digital Research Tools, then, is a artefact (Stanley \& Vandegrift, 2016). As is the XQuery4Humanists curriculum. And, the LibraryWorkflowExchange. Exploring the environment one level higher, many of the challenges we encounter in digital scholarship and scholarly communication fit the mold of what are called "wicked problems" - with the characteristics of being "unique, constantly changing problems that have no single correct solution... lack definability, true-or-false solutions, conclusive endings, scientific tests for solutions, and list of acceptable moves" (Clarke, 2018). For example, what's the best way to share scholarship? How can the humanities prove its relevance? What is the role of the library in the research-intensive university? What does sustainability of curated data look like? Wicked problems. I'd like to propose that digital scholarship and scholarly communication 
offer a method for responding to wicked problems, especially when viewed as acts of creativity/creation.

\section{What changes?}

- Omnipresent in research lifecycle

- Data focused

- Infrastructure aware

- Essential to the community (University and beyond)

Responding directly to the question of how this is changing the research library, I see four near-term revolutions, that will lead to long-term evolution,: Librarianship is/will be 1) omnipresent in the research lifecycle, 2) data-focused, 3) infrastructure aware, and 4) essential to the community, within the university and beyond. Examples of what this might look like on the ground is being newly visible to university administrators, deeply engaged with the classroom/lab, actively involved in the research processes/methodology, integrated with long term projects, co-authors /co-Pl's /collaborators on research outside the field of librarianship, creators/ producers/ disseminators of local knowledge. Much of this is already happening or in development, across many departments in the library.

\section{Omnipresent}

Leaning back on our imagined ecology, the challenge is that the essential organism is, and always has been the collection. In a sense, digital scholarship's propensity to be omnipresent in the research lifecycle is unmooring the collection from the center of the ecosystem. There are two examples of this l'd like to point to, (again examining a near-term revolution that will produce a long-term evolution).

First, our colleagues at the University of Central Florida have designed a workflow that positions the library at key points throughout a typical research (University of Central Florida Libraries Research Lifecycle Committee, 2015). The collection is one important and essential point in this lifecycle, but a view of the whole shows that a shift toward a distributed, end-to-end "library in the life of the user" concept means that digital scholarship and scholarly communication are not peripheral offices, centers, or working groups; they are as central and as essential the collection. Or, as outlined in a digital scholarship manifesto I produced with my colleagues at Florida State, we argued that "digital scholarship places libraries in a central role as a transdisciplinary site of scholarly engagement." Therefore "Rather than locating digital scholarship within an administrative "center," we advocate for the "recentering" of digital scholarship and its activities as a core practice for all the intellectual and knowledge work done in libraries" (Moritz et al., 2017). 
Second, and I think this is a really healthy way to approach this, is the conjoining of the collection with digital scholarship/scholarly communication. This is already occurring in hiring practices - ex. Assoc. Dean for Collections and Scholarly Communication - and in the ubiquity of institutional repositories and digital libraries. The curatorial imperative is expanding to include locally-produced scholarship, AND broadening in definition to include a variety of research outputs i.e. the "value all products of research" concept (Piwowar, 2013). As Danny Kingsley put it, "The solution is to open up the scientific endeavor and to create the means and systems to allow researchers to 'publish' aspects of the research process as it occurs" (Agate et al, 2017). The Collection then is there at the genesis of a research idea, fed by data curation and open access to pre-prints, research posters, and ETDs, stretched to integrate project documentation and electronic lab notebooks from Open Science Framework, developed to include a digital humanities software application, linked with Humanities Commons to pull in syllabi and open educational resources, and making all points of this workflow available for text and data mining via APIs. Omnipresence is being highly visible, valued, and resource-ful.

Lorcan Dempsey calls this the "inside out library", "emphasizing the library's involvement in the process and product of research and learning", where "an increasingly important fusion of the traditional collection management focus and the newer service orientation of libraries is the role of libraries curating content created within their institutions and making it available to a wider audience" (Pinfield, Cox, \& Rutter, 2017). An interviewee in the Society of College, National and University Libraries report on the library of the future states it pretty strongly, saying, "Libraries will face an important choice over the next several years as an institution - whether or not they want to continue to build their prestige around the size of their acquisition budget, in which case their prestige will significantly decline in centraility and important... or whether they want to position themselves as important to the knowledge-creating task of the university in different ways" (Pinfield, Cox, \& Rutter, 2017).

\section{Data Focused and Infrastructure Aware}

I'll combine these two, because I find it impossible to think of them as discrete. A data focused and infrastructure aware library is again not too difficult to imagine - we've brought in Data Carpentry and wrung our hands about Elsevier buying bepress. We've hired CLIR Data Curation Fellows, and built world-class institutional repositories. The transformative aspect, and singular challenge, is convincing our stakeholders (primarily campus administrators like the VP for Research and the CIO) that this is the role of the library, and that we are prepared/preparing to fill that role effectively and efficiently, and that institutional (enterprise) infrastructure "needs to be regarded as a 'node' in the much broader knowledge ecology" (Wolski \& Richardson, 2014). Digital Scholarship and scholarly communication require a deeper, expert level of advocacy, marketing/communication, and language (admin-speak). We tend to focus on reskilling from the ground up (librarian-level) - text-encoding, linked 
open data, python, $R$ - but there is also a need for top-down reskilling in promoting the expertise of the library, and gathering committed, ongoing resources for what Star and Ruhleder call "an ecology of infrastructure" (1996). Jennifer Vinopal and Monica McCormick write, "...grassroots innovation and a few enterprising, proactive staff are no substitute for library leadership providing sustained vision, guidance, and support for these new Initiatives... What is important is that everyone involved in the service development process, from top-level leadership down, should understand how the new service will be guided, how service priorities will be set, who makes which decisions, which success criteria and assessment measures will be used, and how questions will be answered when problems arise" (2013).

There is a lot to be explored in design of a data-focused and infrastructure aware library. Wolski and Richardson, authors of the seminal Model for Institutional Infrastructure to Support Digital Scholarship call for loosely coupled solutions, fed by shared vision and strategy at the institutional level, architected and designed for flexibility. Roger Schonfeld, who has been exploring the shift toward ownership of end-to-end academic workflows, proposed the question, should universities outsource more core research infrastructure? (Schonfeld, 2018) Late last year, the Confederation of Open Access Repositories published a report on behaviours and technical recommendations for next generation repositories (Confederation of Open Access Repositories, 2017). Since 2013 when the Office of Science and Technology Policy issued a memo on public access, data management has become a flash-point topic of conferences, journals (ILSC and JrnI E-SCi LibS), SPEC Kits, and evolving service models in many libraries. What's the near-term application of all this buzz?

Miriam Posner has a blog post that I think about often titled Money and Time. I believe that Digital Scholarship and Scholarly Communication are transforming how we spend our money and time, particularly in terms of data and infrastructure. The day-to-day work of digital scholarship will be, and already is, moving from a focus on projects and tools, to data-production and system-level workflows. There is no way this conversation won't become a resource allocation discussion at the administrative level. Indeed, the 2.5\% Commitment from David Lewis at IUPUI, which was discussed in detail at the CNI meeting last month, "argues that additional contributions from academic libraries are required for infrastructure to support the open scholarly commons and encourages academic libraries to contribute 2.5\% of their total budget to support open infrastructure and content" (Lewis, 2017). We must find a way to 'own the stack, or Elsevier will. As Miriam put it, "If we want to produce truly challenging scholarship and keep our best scholars from burning out, we need to pressure our institutions to, frankly, pay up. You can optimize, streamline, lifehack, and crowdsource almost everything you do - but good scholarship still takes money and time" (Posner, 2016).

We must start talking about infrastructure as a "networked, participatory ecology" because then it evolve from ridgid enterprise technology (servers and software) to people, 
time, skills, workflows. Rather than speccing an infrastructure, lets design/create an information ecology.

\section{Essential to the community}

Any of us would argue vehemently that libraries are always, already essential to the community. I'd imagine that we could count any number of "champions" among research and teaching faculty, graduate students, undergrads and campus partners. The point I'd like to make is that I believe digital scholarship and scholarly communication present an opportunity for us to become indispensable. If we become truly, newly visible with services, expertise, and infrastructure throughout the research environment, our claim on the "heart of the university" will remain recognizable in a way that wouldn't strike fear when talk of budget cuts comes around.

Additionally, I believe that digital scholarship and scholarly communication have led us to a necessary expansion of whom we consider to be our "communities." MIT Libraries Future of Libraries report proposes that we "conceive of communities they serve as concentric circles, from the closely affiliated circle of current students, faculty and staff... [to] the broader global community of scholars". They go on to present the "library as an open platform for global research and learning... rooted in shared values and mission" (MIT Libraries, 2016), aligning with the characteristics of digital scholarship that I identified early on, especially being radically prone toward openness, technology-dependent, and interested in a container/format(s) agnostic future. This alignment is a designerly way of understanding libraries, which "intentionally targets the needs of others," and aims not just solve problems as stated but "emphatically understand the situation and context so that underlying and potentially unknown problems can be solved" (Clarke, 2018).

The only librarianship I've ever known is DPLA, HathiTrust, Open Access, and Digital Humanities. The value of a library to the global knowledge/information ecology is wrapped up inside initiatives like these, integral to their very nature. Aligning the practice of research libraries with the values and technologies and protocols that underlie these kinds of platforms offers to recreate concentric circles of community that we will affect and influence. How do we do that? Advocate with our local colleagues to make their work open (in our repository or anywhere, really), dive deep into our systems/applications to ensure interoperability, inculcate grad students with methodical documentation as core to research processes, and, most importantly, gain trust, respect, and confidence in our work.

\section{Conclusion}

Digital Scholarship is the enactment of the (r)evolutionary impulses on the fringe of librarianship. This style of librarianship is entering a cycle of what l'd like to call 
"generative librarianship", purposefully, ethically, strategically, and systematically creating new things (workflows, systems, tools/technologies, programs, skill sets, etc.) to solve for the challenges (wicked problems) of a networked, global, human-focused, information-rich, academic enterprise. Many libraries are well along this path already, and there is much work to be done. Becoming omnipresent, data-focused, infrastructure-aware, and essential to multiple layers of communities is no small order.

1) Reimagining our collection as one service on a continuum and entangled with new kinds of collecting, 2) strategic investment in infrastructure (especially human!), 3) adapting language that speaks to the new realities of the university, and 4) bringing an community advocacy mindset to our daily interactions are all good starting points.

Rachel Ivy Clarke states that "designers actually change the initial state" of problems they tackle, through framing and reframing from different points of view and imposing a "generating concept" to build from (2018). At the close of a CNI workshop on digital scholarship centers in 2014, Donald Watters, Program Officer for Scholarly Communication at the Mellon Foundation, identified two forms "digital centers" might take - 1) the kind that brings new ideas (methods, tools) in, and 2) the kind that institutionalize the new ideas. I see an evolution of the library where the initial state has been totally transformed through scholarly communication and digital scholarship, where there is no digital center, instead an ecosystem wherein new ideas are generated, incubated, and enveloped into the university, the locality, and the global community.

\section{Works Cited}

Agate, N., Clement, G., Kingsley, D., Searle, S., Vanderjagt, L., Waller, J., ... Newton, M. (2017). From the Ground Up: A Group Editorial on the Most Pressing Issues in Scholarly Communication. Journal of Librarianship and Scholarly Communication, 5(1), eP2196. DOI: http://doi.org/10.7710/2162-3309.2196

Clarke, R. I. (2018). Toward a Design Epistemology for Librarianship. The Library Quarterly, 88(1), 41-59. https://doi.org/10.1086/694872

Confederation of Open Access Repositories. (2017). Behaviours and Technical Recommendations of the COAR Next Generation Repositories Working Group. Retrieved from https://www.coar-repositories.org/files/NGR-Final-Formatted-Report-cc.pdf

Cox, J. (2016). Communicating New Library Roles to Enable Digital Scholarship: A Review Article. New Review of Academic Librarianship, 0(ja), 00-00.

https://doi.org/10.1080/13614533.2016.1181665

Lewis, D. W. (2017). The 2.5\% Commitment (Working Paper). Retrieved from https://scholarworks.iupui.edu/handle/1805/14063 
MIT Libraries. (2016). Institute-wide Task Force on the Future of Libraries. Boston, Massachusetts: Massachusetts Institute of Technology. Retrieved from https://future-of-libraries.mit.edu

Moritz, C., Smart, R., Retteen, A., Hunter, M., Stanley, S., Soper, D., \& Vandegrift, M. (2017). De-Centering and Recentering Digital Scholarship: A Manifesto. Journal of New Librarianship, 2(2). https://doi.org/10.21173/newlibs/3/2

Pinfield, S., Cox, A. M., \& Rutter, S. (2017). Report Mapping the Future of Academic Libraries. Society of College, National, and University Libraries. Retrieved from https://sconul.ac.uk/sites/default/files/documents/SCONUL\%20Report\%20Mapping\%20the \%20Future\%20of\%20Academic\%20Libraries.pdf

Piwowar, H. (2013, January 9). Altmetrics: Value all research products [Comments and Opinion]. https://doi.org/10.1038/493159a

Posner, M. (2016, March 14). Money and Time. Retrieved January 14, 2018, from http://miriamposner.com/blog/money-and-time/

Schonfeld, R. (2018). Big Deal: Should Universities Outsource More Core Research Infrastructure? Ithaka S+R. Retrieved from https://doi.org/10.18665/sr.306032

Stanley, S., \& Vandegrift, M. (2016, October 12). Periodic Table of Digital Research Resources. https://doi.org/10.6084/m9.figshare.3465686.v3

Star, S. L., \& Ruhleder, K. (1996). Steps Toward an Ecology of Infrastructure: Design and Access for Large Information Spaces. Information Systems Research, 7(1), 111-134.

University of Central Florida Libraries Research Lifecycle Committee. (2015, February 10). The research lifecycle at UCF [Online Graphic]. University of Central Florida. Retrieved from http://stars.library.ucf.edu/lib-docs/59

Vinopal, J., \& McCormick, M. (2013). Supporting Digital Scholarship in Research Libraries: Scalability and Sustainability. Journal of Library Administration, 53(1), 27-42. https://doi.org/10.1080/01930826.2013.756689

Wolski, M., \& Richardson, J. (2014). A Model for Institutional Infrastructure to Support Digital Scholarship. Publications, 2(4), 83-99. https://doi.org/10.3390/publications2040083

Full bibliography available at:

https://www.zotero.org/micahvandegrift/items/collectionKey/82AEF6R3 